\title{
Survey on Phenotypic Resistance in Enterococcus Faecalis: Comparison of Expression of Biofilm Related Genes in Persister and Non Persister Cells
}

\author{
Vahab Hasan Kaviar \\ Ilam University of Medical Sciences \\ Saeed Khoshnood \\ Ilam University of Medical Sciences \\ Ebrahim kouhsari \\ Golestan University of Medical Sciences and Health Services
}

\section{Sanaz Yarahmadi}

Ahvaz Jundishapur University of Medical Sciences: Ahvaz Jondishapour University of Medical Sciences

\section{Abbas Maleki}

Ilam University of Medical Sciences

Iraj Pakzad ( $\sim$ lpak26936@gmail.com )

Ilam University of Medical Sciences

\section{Research Article}

Keywords: E. faecalis, Biofilm Formation, Persister, Tolerance, Vancomycin, Phenotypic resistance

Posted Date: July 21 st, 2021

DOI: https://doi.org/10.21203/rs.3.rs-678565/v1

License: (c) (i) This work is licensed under a Creative Commons Attribution 4.0 International License. Read Full License 


\section{Abstract \\ Background}

Currently, phenotypic resistance is a serious therapeutic challenge, and a definitive remedy has not been discovered yet. Biofilm formation and persister cells are two well-studied phenotypic resistance, leading to the recalcitrance and relapse of different chronic infections. It appears that the presence of persister cells in biofilm is the main factor in the relapse of infections and treatment failure. Thus, we aimed to evaluate the expression of biofilm-associated genes in persister and non-persister E. faecalis isolates.

\section{Methods}

Ninety-five clinical E. faecalis isolates were investigated using microtiter broth dilution (MBD) and microtiter plate (MTP) assay to determine the vancomycin-sensitive isolates and biofilm formation, respectively. To this end, 91 vancomycinsensitive $E$. faecalis isolates (biofilm producers) were screened by PCR to determine the presence of biofilm-related genes (gelE, esp, and $a g g$ ). The vancomycin-tolerant isolates were determined by MTP assay. Bacterial persister assay was performed using an enzymatic lysis assay. Finally, the expression of biofilm-related genes was evaluated in persisters and non-persister isolates of $E$. faecalis by real-time PCR assay.

\section{Results}

E. faecalis isolates indicated a high (95.8\%) sensitivity to vancomycin. PCR assay identified gelE, esp, and agg genes in 91 (100\%), 72(79.12), and 74(81.32) of isolates, respectively. All E. faecalis biofilm producers were tolerant to vancomycin, and minimum bactericidal concentration for biofilms (MBCB) was $>2500 \mu \mathrm{g} / \mathrm{ml}$. Based on enzymatic lysis assay, among 91 isolates, only 3 persister were isolated. The increased expression level of biofilm-related genes was observed in persister than non-persister $E$. faecalis isolates.

\section{Conclusion}

The expression of biofilm-related genes is higher in persister than non-persister isolates of $E$. faecalis.

\section{Introduction}

Enterococcus faecalis emerges as the most common hospital-acquired pathogen(1). A major attribute of enterococcal infections is phenotypic and genotypic resistance $(2,3)$. The phenotypic resistance, recognized as a prominent achievement of bacteria, which dramatically enhances the tolerance against a variety of antibiotic classes (4). Currently, investigating the phenotypic resistance remains as a controversial concern that has received particular attention in microbiology.

Biofilm formation, the first well-studied phenotypic resistance, is associated with a broad range of infections ranging from exogenous device-related to chronic tissue infections (5-7). Now, the question arises that what factor(s) do (es) increase the biofilm tolerance. The existence of persister cells defined as dormant cells or sub-population with low-metabolic activity and also known as other phenotypic resistance in biofilms might represent the reason for the drug tolerance (8). Indeed, persisters are dormant (slow-growing) or growth-arrested phenotypic variants of normal cells in bacterial populations and are transiently antibiotic-tolerant cells. The presence of persister cells in biofilm is deemed as the main factor responsible for the relapse of infections and treatment failure (8-10). Given that persisters are dormant and inert cells, they can be prey for the immune system factors. Biofilm formation would be a survival strategy for defenseless 
persister cells (11). Consequently, these observations raised the probability that persister isolates might show more proclivity to biofilm formation. The combination of these phenotypic resistances (biofilm/persister infections) are thought to underlie the dramatically enhances the antibiotic tolerance, treatment failure and relapse of chronic infections. Thus, research in this field is valuable for public health (12). Herein, we aimed to investigate the antibiotic-tolerant biofilm to identify the persisters and evaluate the expression of biofilm-associated genes in persisters and non-persisters of $E$. faecalis isolates.

\section{Methods}

\subsection{Study Design and E. faecalis Isolates}

This cross-sectional study was conducted on 95 clinical E. faecalis isolates from September 2019 to October 2020. The isolates were previously obtained from Medical Microbiology Department, School of Medicine, Ahvaz Jundishapur University of Medical Sciences, Ahvaz, Iran and also from Clinical Microbiology Research Center, llam University of Medical Sciences, llam, Iran. All the $E$. faecalis isolates were confirmed by polymerase chain reaction (PCR) with specific primers for the 16SrRNA gene (Table 1). The clinical isolates were stored in Tryptic soy broth (TSB; Merck, Germany) containing $20 \%$ glycerol at $-70^{\circ} \mathrm{C}$ until further analysis. The study protocol was approved by the Ethics Committee of Ilam University of Medical Sciences (IR.MEDILAM.REC.1397.046).

Table 1

Specific primer pairs used for PCR and Real Time-PCR

\begin{tabular}{|c|c|c|c|c|c|c|c|}
\hline Gene & & $\begin{array}{l}\text { Initial } \\
\text { denaturation }\end{array}$ & Denaturation & Annealing & Extension & $\begin{array}{l}\text { Final } \\
\text { Extension }\end{array}$ & $\begin{array}{l}\text { Cycle } \\
\text { number }\end{array}$ \\
\hline $\begin{array}{l}16 S \\
\text { rRNA }\end{array}$ & $\begin{array}{l}\text { Temperature }\left({ }^{\circ} \mathrm{C}\right. \\
) / \text { Time }\end{array}$ & $95 / 5 \min$ & $95 / 45 \mathrm{sec}$ & $\begin{array}{l}62 / 40 \\
\text { sec }\end{array}$ & $\begin{array}{l}72 / 1 \\
\min \end{array}$ & $\begin{array}{l}72 / \\
10 \mathrm{~min}\end{array}$ & 37 \\
\hline gelE & $\begin{array}{l}\text { Temperature }\left({ }^{\circ} \mathrm{C}\right. \\
) / \text { Time }\end{array}$ & $95 / 5$ min & $95 / 50 \mathrm{sec}$ & $\begin{array}{l}57 / 1 \\
\min \end{array}$ & $\begin{array}{l}72 / 50 \\
\text { sec }\end{array}$ & $\begin{array}{l}72 \\
/ 10 \min \end{array}$ & \\
\hline esp & $\begin{array}{l}\text { Temperature }\left({ }^{\circ} \mathrm{C}\right. \\
) / \text { Time }\end{array}$ & $95 / 5 \mathrm{~min}$ & $95 / 50 \mathrm{sec}$ & $\begin{array}{l}50 / 1 \\
\min \end{array}$ & $\begin{array}{l}72 / 50 \\
\text { sec }\end{array}$ & $\begin{array}{l}72 / 10 \\
\min \end{array}$ & \\
\hline$a g g$ & $\begin{array}{l}\text { Temperature }\left({ }^{\circ} \mathrm{C}\right. \\
) / \text { Time }\end{array}$ & $95 / 5 \min$ & $95 / 45 \mathrm{sec}$ & $\begin{array}{l}58 / 1 \\
\min \end{array}$ & $\begin{array}{l}72 / 50 \\
\text { sec }\end{array}$ & $\begin{array}{l}72 / \\
10 \mathrm{~min}\end{array}$ & \\
\hline
\end{tabular}

\subsection{Minimum Inhibitory Concentration (MIC) of Vancomycin in E. faecalis Isolates}

In order to determine vancomycin-sensitive strains, the MICs of vancomycin (Sigma Aldrich, USA) in E. faecalis isolates were determined by the microtiter broth dilution method in Mueller-Hinton Broth (MHB, Condalab, Spain) according to clinical and laboratory standard institute (CLSI) guidelines (13). The MIC $\geq 32 \mu \mathrm{g} / \mathrm{mL}$ and $\leq 4 \mu \mathrm{g} / \mathrm{mL}$ was proposed as the breakpoint of resistance and sensitive, respectively. E. faecalis ATCC 29212 and E. faecalis ATCC 51299 were used for the quality control.

\subsection{Biofilm Assay}

Biofilm formation was performed by the microtiter plate (MTP) and crystal violet assay, as described elsewhere (14). Briefly, E. faecalis overnight cultures were inoculated in TSB (Merck) containing $0.25 \%$ glucose. The culture was adjusted to obtain 0.5 McFarland standard, and bacterial suspension was diluted 1:100 in a fresh TSB. Thereafter, $200 \mu$ of each bacterial suspension was distributed to three wells of the sterile 96-well polystyrene MTP, and the content was incubated at $37^{\circ} \mathrm{C}$ for $48 \mathrm{~h}$. After three times washes with phosphate-buffered saline (PBS), unattached bacterial cells were removed and 
then left to dry. Biofilm was stained with $200 \mu \mathrm{L}$ of crystal violet $2 \%(\mathrm{w} / \mathrm{v})$ for $15 \mathrm{~min}$, and wells were gently rewashed with water. After the wells were dried, $200 \mu \mathrm{L}$ of $33 \%(\mathrm{v} / \mathrm{v})$ glacial acetic acid was used to re-solubilize the dye bound to the adherent cells. The optical density (OD) value was measured at $545 \mathrm{~nm}$ using an ELISA reader (Biotech, USA), and the mean OD of the three wells was then calculated. The adherence capabilities of the isolates were classified into four categories; three standard deviations (SDs) above the mean OD of the negative control (broth only) was considered as the cut-off optical density (ODc). The isolates were categorized as follows: $\mathrm{OD} \leq \mathrm{ODc}, \mathrm{ODc}<\mathrm{OD} \leq 2 \times \mathrm{ODc}, 2 \times \mathrm{ODc}<\mathrm{OD} \leq 4 \times$ ODc and $4 \times$ ODc $<$ OD, implying that the bacteria were non-adherent, weakly adherent, moderately adherent, and strongly adherent, respectively.

\subsection{Molecular Detection of Biofilm-Related Genes}

Genomic DNA was extracted from the fresh overnight cultures of the isolates as explained before (15). PCR was carried out for the detection of biofilm-related genes (esp, agg and $g e / E$ ) as previously described (16-18). The primers were synthesized by Macrogene (Macrogene, South Korea), and specific primer pairs for different genes are shown in Table 1. PCR was performed in a thermocycler (Bio-Rad, USA) with $25 \mu \mathrm{l}$ of reaction mixture containing $2 \mu \mathrm{L}$ of each forward and reverse primer, $12.5 \mu \mathrm{L}$ of Master Mix 2x (Solis BioDyne, Estonia), $7 \mu \mathrm{L}$ of nuclease-free water, and $1.5 \mu \mathrm{L}$ of template DNA. The PCR program is represented in Table 2. PCR products were analyzed by electrophoresis (Bio-Rad, USA) on 1\% (w/v) agarose gels (SinaClon, Iran), and the amplified products were subjected to DNA sequencing by Bioneer (South Korea).

Table 2

PCR program for molecular detection of genes

\begin{tabular}{|llll|}
\hline Gene & Sequence (5'-3') & $\begin{array}{l}\text { Amplicon size } \\
\text { (bp) }\end{array}$ & Reference \\
\hline agg & F : GATACAAAGCCAATGTCGTTCCT & 101 & $(16)$ \\
& R: TAAAGAGTCGCCACGTTTCACA & & \\
\hline esp & F: GCATCAGTATTAGTTGGT & 196 & $(17)$ \\
& R: TTCCTTGTAACACATCAC & & \\
\hline $16 S$ rRNA & F: CCGAGTGCTTGCACTCAATTGG & 137 & $(22)$ \\
& R: CTCTTATGCCATGCGGCATAAAC & & \\
\hline
\end{tabular}

\subsection{Minimal Bactericidal Concentration for Biofilm (MBCB) of E. faecalis Isolates}

The MBCB of E. faecalis isolates was determined as per a method described formerly (19) with modifications in the isolation of persister cells. In brief, $200 \mu \mathrm{L}$ of each diluted culture (as previously noted) was distributed to the individual wells of 96-well MTP and incubated at

$37^{\circ} \mathrm{C}$ for $48 \mathrm{~h}$. The following day, the suspension was discarded and washed with sterile PBS. Afterward, $200 \mu \mathrm{l}$ of the desired antibiotic dilution was added (diluted in normal saline, ranging from 0 to $2,500 \mu \mathrm{g} / \mathrm{ml} \mathrm{in} 250-\mu \mathrm{g} / \mathrm{ml}$ increments). After the incubation of the plates at $35^{\circ} \mathrm{C}$ for $24 \mathrm{~h}$, the antibiotic was discarded, and then the biofilms were slowly sonicated. The content of each well was diluted with fresh media and cultured on blood agar (BA; Condalab, Spain) plates.

\subsection{Persister Assay}


The enzymatic lysis method was carried out as previously described (20). Briefly, for persister isolation, $1 \mathrm{~mL}$ of overnight culture and $200 \mu$ l of the lysis solution (SinaClon, Iran) were added to a $15 \mathrm{~mL}$ falcon. The mixture was homogenized by vortex for 10 seconds, and then incubated at room temperature. After 10 minutes, $200 \mu$ of the enzymatic lysis solution (45 mg, 48539 units/mg, of lysozyme [Sigma Aldrich] in $1 \mathrm{ml}$ TE buffer) was added to the falcon and slowly mixed by inverting. The mixture was incubated at $200 \mathrm{rpm}$ at $37^{\circ} \mathrm{C}$ for $15 \mathrm{~min}$, serially diluted and eventually plated on blood agar (Condalab, Spain). The E. coli TOP10 was used for negative control.

\subsection{Persister Killing Assay}

Persister killing assay was accomplished in compliance with a former method (21). In summary, the stock solution was prepared by $0.5 \mathrm{mg}$ of mitomycin C (MMC; Sigma Aldrich) in $1 \mathrm{ml}$ of distilled water. The MIC of different concentration of MMC was measured by broth microdilution in TSB. Based on the lack of turbidity, the wells were considered as MIC. For planktonic cells, $1 \times$ MIC and 5× MIC were affected at $3 \mathrm{~h}$-interval incubation, and then cell viability was determined by serially diluted and plated on blood agar. For biofilm, $1 \times$ MIC and $5 \times$ MIC were affected on biofilm formed for $16 \mathrm{~h}$. The next day, the suspension was discarded and washed with sterile PBS. Finally, biofilms were gently sonicated, and the content of each well was serially diluted and plated on BA.

\subsection{Expression of Biofilm-Related Genes}

Quantitative real-time PCR (qPCR) assay was performed to determine the expression level of biofilm-related genes (esp, $a g g$, and $g e / E$ ) in persister and non-persister cells in triplicate. RNA was extracted with the RNA extraction kit (SinaClon, Iran). The quality and integrity of the total RNA assessed with a NanoDrop spectrophotometer (Thermo Fisher Scientific, Waltham, MA, USA) were electrophoresed on $1 \%$ agarose gel. In following, cDNA was synthesized by oligo dT primers according to the manufacturer's instructions (cDNA synthesis kit; Takara, Tokyo, Japan). The specific primers are presented in Table 1. To carry out qPCR, the 16srRNA gene was used as the internal reference gene. The reaction mixture, in a total volume of $25 \mu \mathrm{L}$, contained $2 \mu \mathrm{L}$ of each forward and reverse primer, $12.5 \mu \mathrm{L}$ of $2 \times$ real-time PCR Master Mix (SYBR Green; Fermentas, Lithuania), $7 \mu \mathrm{L}$ of nuclease-free water, and $1.5 \mu \mathrm{L}$ of cDNA. Moreover, negative controls including all the elements of the reaction mixture except the template cDNA were performed in every analysis, and no amplified cDNA product was ever detected. Real-time PCR system (CFX96 real-time PCR detection system, Bio-Rad, California, USA) was carried out in triplicate according to the following conditions: an initial holding at $95^{\circ} \mathrm{C}$ for 5 minutes, followed by 38 cycles of denaturation at $95^{\circ} \mathrm{C}$ for 45 seconds, annealing at $58^{\circ} \mathrm{C}$ for 60 seconds, and extension at $68^{\circ} \mathrm{C}$ for 30 seconds. The relative expression fold changes of mRNAs were calculated using the $2^{-\Delta \Delta C t}$ method.

\section{Results}

\subsection{Biofilm Formation and detection of related genes}

The vancomycin sensitivity rate was $95.8 \%$ (91/95) in all the clinical E. faecalis isolates. In this study, the vancomycinsensitive isolates were selected for subsequent analysis. Our findings showed the high ability (98.9\%) of biofilm formation in clinical E. faecalis isolates. Vancomycin-sensitive isolates $(n=91)$ were characterized into four groups: strong biofilm $(24 / 91 ; 26.38 \%)$, moderate $(44 / 91 ; 48.35 \%)$, weak $(22 / 91 ; 24.17 \%)$, and non-biofilm producer $(1 / 91 ; 1.1 \%)$.

Based on the results, esp, agg, and gelE genes were detected in 72 (79.12\%), 74 (81.32\%) and 91 (100\%) isolates, respectively (Table 3). Fifty- six (61.53\%) isolates had these genes simultaneously, and all the isolates included at least one biofilm-related gene. Coexistence genes, esp, agg, and gelE, were observed in 22 strong biofilm producer E. faecalis isolates. The relationship between the biofilm formation and related genes in $E$. faecalis isolates is presented in Table 4 . 
Table 3

Characteristics of E. faecalis isolates

\begin{tabular}{|c|c|c|c|c|c|c|c|c|c|}
\hline $\begin{array}{l}\text { Strain } \\
\text { ID }\end{array}$ & $\begin{array}{l}\text { Vancomycin } \\
M I C(\mu \mathrm{g} / \mathrm{ml})\end{array}$ & $\begin{array}{l}\text { Biofilm } \\
\text { formation }\end{array}$ & $\begin{array}{l}\text { Biofilm } \\
\text { Genes }\end{array}$ & $\begin{array}{l}\text { Persister } \\
\text { cell }\end{array}$ & $\begin{array}{l}\text { Strain } \\
\text { ID }\end{array}$ & $\begin{array}{l}\text { Vancomycin } \\
\text { MIC }(\mu \mathrm{g} / \mathrm{ml})\end{array}$ & $\begin{array}{l}\text { Biofilm } \\
\text { formation }\end{array}$ & $\begin{array}{l}\text { Biofilm } \\
\text { Genes }\end{array}$ & $\begin{array}{l}\text { Persister } \\
\text { cell }\end{array}$ \\
\hline Ef 1 & 0.5 & Moderate & $\begin{array}{l}\text { gelE, } \\
\text { esp, } \\
\text { agg }\end{array}$ & - & Ef 47 & 0.5 & Weak & $\begin{array}{l}\text { gelE, } \\
\text { esp }\end{array}$ & - \\
\hline Ef 2 & 0.5 & Strong & $\begin{array}{l}\text { gelE, } \\
\text { esp, } \\
\text { agg }\end{array}$ & Persister & Ef 48 & 0.5 & Moderate & $\begin{array}{l}\text { gelE, } \\
\text { esp }\end{array}$ & - \\
\hline Ef 3 & 0.25 & Strong & $\begin{array}{l}\text { gelE, } \\
\text { esp, } \\
\text { agg }\end{array}$ & - & Ef 49 & 0.5 & Moderate & $\begin{array}{l}\text { gelE, } \\
\text { esp, } \\
\text { agg }\end{array}$ & - \\
\hline Ef 4 & 0.5 & Weak & $\begin{array}{l}\text { gelE, } \\
\text { agg }\end{array}$ & - & Ef 50 & 0.5 & Strong & $\begin{array}{l}\text { gelE, } \\
\text { esp, } \\
\text { agg }\end{array}$ & Persister \\
\hline Ef 5 & 0.5 & Moderate & $\begin{array}{l}\text { gelE, } \\
\text { esp, } \\
\text { agg }\end{array}$ & - & Ef 51 & 0.25 & Moderate & $\begin{array}{l}\text { gelE, } \\
\text { esp, } \\
\text { agg }\end{array}$ & - \\
\hline Ef 6 & 0.25 & Weak & $\begin{array}{l}\text { gelE, } \\
\text { agg }\end{array}$ & - & Ef 52 & 0.5 & Weak & $\begin{array}{l}\text { gelE, } \\
\text { agg }\end{array}$ & - \\
\hline Ef 7 & 0.5 & Strong & $\begin{array}{l}\text { gelE, } \\
\text { esp }\end{array}$ & - & Ef 53 & 0.5 & Strong & $\begin{array}{l}\text { gelE, } \\
\text { esp, } \\
\text { agg }\end{array}$ & - \\
\hline Ef 8 & 0.125 & Moderate & $\begin{array}{l}\text { gelE, } \\
\text { esp, } \\
\text { agg }\end{array}$ & - & Ef 54 & 0.5 & Moderate & $\begin{array}{l}\text { gelE, } \\
\text { esp }\end{array}$ & - \\
\hline Ef 9 & 0.25 & Moderate & $\begin{array}{l}\text { gelE, } \\
\text { esp, } \\
\text { agg }\end{array}$ & - & Ef 55 & 0.25 & Weak & $\begin{array}{l}\text { gelE, } \\
\text { esp }\end{array}$ & - \\
\hline Ef 10 & 0.25 & Moderate & $\begin{array}{l}\text { gelE, } \\
\text { esp, } \\
\text { agg }\end{array}$ & - & Ef 56 & 0.25 & Weak & $\begin{array}{l}\text { gelE, } \\
\text { agg }\end{array}$ & - \\
\hline Ef 11 & 0.5 & Weak & $\begin{array}{l}\text { gelE, } \\
\text { agg }\end{array}$ & - & Ef 57 & 0.5 & Strong & $\begin{array}{l}\text { gelE, } \\
\text { esp }\end{array}$ & - \\
\hline Ef 12 & 0.25 & Strong & $\begin{array}{l}\text { gelE, } \\
\text { esp, } \\
\text { agg }\end{array}$ & - & Ef 58 & 0.25 & Strong & $\begin{array}{l}\text { gelE, } \\
\text { esp, } \\
\text { agg }\end{array}$ & - \\
\hline Ef 13 & 0.125 & Weak & $\begin{array}{l}\text { gelE, } \\
\text { agg }\end{array}$ & - & Ef 59 & 0.5 & Strong & $\begin{array}{l}\text { gelE, } \\
\text { esp, } \\
\text { agg }\end{array}$ & - \\
\hline Ef 14 & 0.25 & Moderate & $\begin{array}{l}\text { gel } E_{,} \\
\text {agg }\end{array}$ & - & Ef 60 & 0.125 & Moderate & $\begin{array}{l}\text { gel } E_{1,} \\
\text { agg }\end{array}$ & - \\
\hline Ef 15 & 0.5 & Weak & $\begin{array}{l}\text { gelE, } \\
\text { esp, } \\
\text { agg }\end{array}$ & - & Ef 61 & 0.5 & Weak & $\begin{array}{l}\text { gelE, } \\
\text { esp }\end{array}$ & - \\
\hline Ef 16 & 0.25 & Moderate & $\begin{array}{l}\text { gelE, } \\
\text { esp, } \\
\text { agg }\end{array}$ & - & Ef 62 & 0.5 & Moderate & $\begin{array}{l}\text { gelE, } \\
\text { esp, } \\
\text { agg }\end{array}$ & - \\
\hline
\end{tabular}




\begin{tabular}{|c|c|c|c|c|c|c|c|c|c|}
\hline $\begin{array}{l}\text { Strain } \\
\text { ID }\end{array}$ & $\begin{array}{l}\text { Vancomycin } \\
M I C(\mu \mathrm{g} / \mathrm{ml})\end{array}$ & $\begin{array}{l}\text { Biofilm } \\
\text { formation }\end{array}$ & $\begin{array}{l}\text { Biofilm } \\
\text { Genes }\end{array}$ & $\begin{array}{l}\text { Persister } \\
\text { cell }\end{array}$ & $\begin{array}{l}\text { Strain } \\
\text { ID }\end{array}$ & $\begin{array}{l}\text { Vancomycin } \\
\text { MIC }(\mu \mathrm{g} / \mathrm{ml})\end{array}$ & $\begin{array}{l}\text { Biofilm } \\
\text { formation }\end{array}$ & $\begin{array}{l}\text { Biofilm } \\
\text { Genes }\end{array}$ & $\begin{array}{l}\text { Persister } \\
\text { cell }\end{array}$ \\
\hline Ef 17 & 0.5 & Moderate & $\begin{array}{l}\text { gelE, } \\
\text { esp, } \\
\text { agg }\end{array}$ & - & Ef 63 & 0.25 & Weak & $\begin{array}{l}\text { gelE, } \\
\text { agg }\end{array}$ & - \\
\hline Ef 18 & 0.5 & Strong & $\begin{array}{l}\text { gelE, } \\
\text { esp, } \\
\text { agg }\end{array}$ & Persister & Ef 64 & 0.5 & Moderate & $\begin{array}{l}\text { gelE, } \\
\text { esp, } \\
\text { agg }\end{array}$ & - \\
\hline Ef 19 & 0.5 & Moderate & $\begin{array}{l}\text { gelE, } \\
\text { esp, } \\
\text { agg }\end{array}$ & - & Ef 65 & 0.25 & Strong & $\begin{array}{l}\text { gelE, } \\
\text { esp, } \\
\text { agg }\end{array}$ & - \\
\hline Ef 20 & 0.125 & Weak & $\begin{array}{l}\text { gelE, } \\
\text { agg }\end{array}$ & - & Ef 66 & 0.5 & Moderate & $\begin{array}{l}\text { gelE, } \\
\text { esp }\end{array}$ & - \\
\hline Ef 21 & 0.5 & Moderate & $\begin{array}{l}\text { gelE, } \\
\text { esp }\end{array}$ & - & Ef 67 & 0.5 & Moderate & $\begin{array}{l}\text { gelE, } \\
\text { esp, } \\
\text { agg }\end{array}$ & - \\
\hline Ef 22 & 0.5 & Moderate & $\begin{array}{l}\text { gelE, } \\
\text { agg }\end{array}$ & - & Ef 68 & 0.25 & Weak & $\begin{array}{l}\text { gelE, } \\
\text { agg }\end{array}$ & - \\
\hline Ef 23 & 0.5 & Moderate & $\begin{array}{l}\text { gelE, } \\
\text { esp, } \\
\text { agg }\end{array}$ & - & Ef 69 & 0.25 & Moderate & $\begin{array}{l}\text { gelE, } \\
\text { esp, } \\
\text { agg }\end{array}$ & - \\
\hline Ef 24 & 0.5 & Moderate & $\begin{array}{l}\text { gelE, } \\
\text { esp, } \\
\text { agg }\end{array}$ & - & Ef 70 & 0.5 & Strong & $\begin{array}{l}\text { gelE, } \\
\text { esp, } \\
\text { agg }\end{array}$ & - \\
\hline Ef 25 & 0.25 & Weak & $\begin{array}{l}\text { gelE, } \\
\text { agg }\end{array}$ & - & Ef 71 & 0.25 & Moderate & $\begin{array}{l}\text { gelE, } \\
\text { esp, } \\
\text { agg }\end{array}$ & - \\
\hline Ef 26 & 0.5 & Moderate & $\begin{array}{l}\text { gelE, } \\
\text { esp, } \\
\text { agg }\end{array}$ & - & Ef 72 & 0.5 & Weak & $\begin{array}{l}\text { gelE, } \\
\text { agg }\end{array}$ & - \\
\hline Ef 27 & 0.25 & Moderate & $\begin{array}{l}\text { gelE, } \\
\text { esp, } \\
\text { agg }\end{array}$ & - & Ef 73 & 0.5 & Weak & $\begin{array}{l}\text { gelE, } \\
\text { esp }\end{array}$ & - \\
\hline Ef 28 & 0.25 & Moderate & $\begin{array}{l}\text { gelE, } \\
\text { esp }\end{array}$ & - & Ef 74 & 0.25 & Moderate & $\begin{array}{l}\text { gelE, } \\
\text { esp }\end{array}$ & - \\
\hline Ef 29 & 0.5 & Moderate & $\begin{array}{l}\text { gelE, } \\
\text { esp, } \\
\text { agg }\end{array}$ & - & Ef 75 & 0.25 & Moderate & $\begin{array}{l}\text { gelE, } \\
\text { esp, } \\
\text { agg }\end{array}$ & - \\
\hline Ef 30 & 0.5 & Strong & $\begin{array}{l}\text { gelE, } \\
\text { esp, } \\
\text { agg }\end{array}$ & - & Ef 76 & 0.25 & Strong & $\begin{array}{l}\text { gelE, } \\
\text { esp, } \\
\text { agg }\end{array}$ & - \\
\hline Ef 31 & 0.5 & Moderate & $\begin{array}{l}\text { gelE, } \\
\text { esp, } \\
\text { agg }\end{array}$ & - & Ef 77 & 0.5 & Moderate & $\begin{array}{l}\text { gelE, } \\
\text { esp }\end{array}$ & - \\
\hline Ef 32 & 0.25 & Strong & $\begin{array}{l}\text { gelE, } \\
\text { esp, } \\
\text { agg }\end{array}$ & - & Ef 78 & 0.5 & Moderate & $\begin{array}{l}\text { gelE, } \\
\text { esp, } \\
\text { agg }\end{array}$ & - \\
\hline Ef 33 & 0.5 & Moderate & $\begin{array}{l}\text { gelE, } \\
\text { esp }\end{array}$ & - & Ef 79 & 0.5 & Weak & $\begin{array}{l}\text { gelE, } \\
\text { agg }\end{array}$ & - \\
\hline
\end{tabular}




\begin{tabular}{|c|c|c|c|c|c|c|c|c|c|}
\hline $\begin{array}{l}\text { Strain } \\
\text { ID }\end{array}$ & $\begin{array}{l}\text { Vancomycin } \\
M I C(\mu \mathrm{g} / \mathrm{ml})\end{array}$ & $\begin{array}{l}\text { Biofilm } \\
\text { formation }\end{array}$ & $\begin{array}{l}\text { Biofilm } \\
\text { Genes }\end{array}$ & $\begin{array}{l}\text { Persister } \\
\text { cell }\end{array}$ & $\begin{array}{l}\text { Strain } \\
\text { ID }\end{array}$ & $\begin{array}{l}\text { Vancomycin } \\
\text { MIC }(\mu \mathrm{g} / \mathrm{ml})\end{array}$ & $\begin{array}{l}\text { Biofilm } \\
\text { formation }\end{array}$ & $\begin{array}{l}\text { Biofilm } \\
\text { Genes }\end{array}$ & $\begin{array}{l}\text { Persister } \\
\text { cell }\end{array}$ \\
\hline Ef 34 & 0.5 & Weak & $\begin{array}{l}\text { gelE, } \\
\text { agg }\end{array}$ & - & Ef 80 & 0.25 & Moderate & $\begin{array}{l}\text { gelE, } \\
\text { esp, } \\
\text { agg }\end{array}$ & - \\
\hline Ef 35 & 0.25 & Weak & $\begin{array}{l}\text { gelE, } \\
\text { esp }\end{array}$ & - & Ef 81 & 0.5 & Strong & $\begin{array}{l}\text { gelE, } \\
\text { esp, } \\
\text { agg }\end{array}$ & - \\
\hline Ef 36 & 0.25 & Moderate & $\begin{array}{l}\text { gelE, } \\
\text { esp, } \\
\text { agg }\end{array}$ & - & Ef 82 & 0.25 & Moderate & $\begin{array}{l}\text { gelE, } \\
\text { esp, } \\
\text { agg }\end{array}$ & - \\
\hline Ef 37 & 0.25 & Strong & $\begin{array}{l}\text { gelE, } \\
\text { esp, } \\
\text { agg }\end{array}$ & - & Ef 83 & 0.5 & Strong & $\begin{array}{l}\text { gelE, } \\
\text { esp, } \\
\text { agg }\end{array}$ & - \\
\hline Ef 38 & 0.5 & Moderate & $\begin{array}{l}\text { gelE, } \\
\text { esp, } \\
\text { agg }\end{array}$ & - & Ef 84 & 0.5 & Weak & $\begin{array}{l}\text { gelE, } \\
\text { esp }\end{array}$ & - \\
\hline Ef 39 & 0.125 & Weak & $\begin{array}{l}\text { gelE, } \\
\text { agg }\end{array}$ & - & Ef 85 & 0.25 & Moderate & $\begin{array}{l}\text { gelE, } \\
\text { esp, } \\
\text { agg }\end{array}$ & - \\
\hline Ef 40 & 0.5 & Moderate & $\begin{array}{l}\text { gelE, } \\
\text { esp, } \\
\text { agg }\end{array}$ & - & Ef 86 & 0.25 & $\begin{array}{l}\text { Non- } \\
\text { Biofilm }\end{array}$ & gelE & - \\
\hline Ef 41 & 0.25 & Moderate & $\begin{array}{l}\text { gelE, } \\
\text { esp, } \\
\text { agg }\end{array}$ & - & Ef 87 & 0.5 & Strong & $\begin{array}{l}\text { gelE, } \\
\text { esp, } \\
\text { agg }\end{array}$ & - \\
\hline Ef 42 & 0.5 & Weak & $\begin{array}{l}\text { gelE, } \\
\text { agg }\end{array}$ & - & Ef 88 & 0.25 & Strong & $\begin{array}{l}\text { gelE, } \\
\text { esp, } \\
\text { agg }\end{array}$ & - \\
\hline Ef 43 & 0.25 & Strong & $\begin{array}{l}\text { gelE, } \\
\text { esp, } \\
\text { agg }\end{array}$ & - & Ef 89 & 0.125 & Moderate & $\begin{array}{l}\text { gelE, } \\
\text { esp, } \\
\text { agg }\end{array}$ & - \\
\hline Ef 44 & 0.25 & Moderate & $\begin{array}{l}\text { gelE, } \\
\text { esp, } \\
\text { agg }\end{array}$ & - & Ef 90 & 0.5 & Moderate & $\begin{array}{l}\text { gelE, } \\
\text { esp, } \\
\text { agg }\end{array}$ & - \\
\hline Ef 45 & 0.125 & Strong & $\begin{array}{l}\text { gelE, } \\
\text { esp, } \\
\text { agg }\end{array}$ & - & Ef 91 & 0.5 & Strong & $\begin{array}{l}\text { gelE, } \\
\text { esp, } \\
\text { agg }\end{array}$ & - \\
\hline Ef 46 & 0.25 & Strong & $\begin{array}{l}\text { gelE, } \\
\text { esp, } \\
\text { agg }\end{array}$ & - & & & & & \\
\hline
\end{tabular}


Table 4

The Relationship between biofilm formation and related genes in E. faecalis Strains

\begin{tabular}{|l|lllllll|}
\hline Biofilm Intensity (No.) & \multicolumn{2}{l}{ gelE No (\%) } & esp No (\%) & \multicolumn{3}{l|}{ agg No (\%) } \\
\cline { 2 - 7 } & Positive & Negative & Positive & Negative & Positive & Negative \\
\hline Strong (24) & $24(100)$ & 0 & $24(100)$ & 0 & $22(92)$ & $2(8)$ \\
\hline Moderate (44) & $44(100)$ & 0 & $41(93)$ & $3(7)$ & $36(82)$ & $8(18)$ \\
\hline Weak (22) & $22(100)$ & 0 & $7(32)$ & $15(68)$ & $16(73)$ & $6(27)$ \\
\hline Non- Biofilm forming (1) & $1(100)$ & 0 & 0 & $1(100)$ & 0 & $1(100)$ \\
\hline Total (91) & $91(100)$ & 0 & $72(79.12)$ & $19(20.88)$ & $74(81.32)$ & $17(18.68)$ \\
\hline
\end{tabular}

About determination of the MBCB of E. faecalis isolates for identification of tolerant biofilm and persister cells, the cells resided in all of the biofilms indicated extremely high tolerance to vancomycin with $\mathrm{MBCB}>2500 \mu \mathrm{g} / \mathrm{ml}$.

\subsection{Persister Assay}

Although all biofilms had a high tolerance to vancomycin, but the enzymatic lysis assay displayed that 3 isolates (strong biofilm) were persister and other 88 isolates were non-persister cells. About persister killing assay, the results suggested that $5 \times \mathrm{MIC}(5 \mu \mathrm{g} / \mathrm{ml})$ of MMC could completely eradicate the planktonic persister cells at $3 \mathrm{~h}$-interval incubation and led to the reduction of viable cells in the biofilm. However, it could not fully eliminate the biofilm at $24 \mathrm{~h}$-interval incubation. We tested the $10 \mu \mathrm{g} / \mathrm{ml}$ but could not due to dispersal of biofilm. The MBC of MMC for E. faecalis persister cells in biofilm state was $>10 \mu \mathrm{g} / \mathrm{ml}$.

\subsection{Biofilm-Associated Gene Expression in Persisters and Non- Persisters}

In following, we determined the expression of the esp, agg, and gelEgenes in three persisters (Ef 2, Ef 18 and Ef 50) and seven non-persisters isolates (Ef 3, Ef 12, Ef 30, Ef 37, Ef 43, Ef 46 and Ef 58). Overexpression means that the isolates have fourfold increase in the expression level of genes compared with the reference strain E. faecalis ATCC 29212. The esp, agg, and $g$ elE genes were overexpressed in three persisters isolates, but their expression did not change in seven non persisters isolates. In persister isolates, the agg gene had lower expression than the esp and gelE genes (Fig. 1).

\section{Discussion}

Biofilms are actually the architecture of an intelligent response made by certain bacteria as has long been considered as the main cause of their survival. In contrast to some hypotheses that antibiotics can readily traverse the biofilm layers and resulting in dispersion of them, it has been established in earlier studies, some biofilm-forming bacteria are able to temporarily tolerate extremely high concentration of antibiotics $(22,23)$. Indeed, biofilm barriers are a type of scape strategy to circumvent the immune system factors $(8,12,24)$. Our results revealed that the expression of biofilm-related genes was higher in persister than non-persister isolates of $E$. faecalis. Moreover, most of E. faecalis isolates (95.8\%) were vancomycin sensitive, which supports the finding of a meta-analysis study (25). The presence of gelE in all of our strains reflected the significant function of gelatinase in biofilm formation (26), which has previously been reported in the literature $(27,28)$. Additionally, our findings, in line with that of Tendulkar et al. (28), unmasked a direct link between the presence of esp gene with the biofilm intensity. Evidence has pointed out that persisters are the main factor underlying drug tolerance $(8,29,30)$. Interestingly, in the current study, 3 isolates were persisters but, the cells embedded in all of the biofilms could dramatically tolerate vancomycin (MBCB $>2500 \mu \mathrm{g} / \mathrm{ml})$, which is consistent with the finding of Butini et al. (31) who 
indicated that the high concentration of vancomycin (i.e. $>1024 \mu \mathrm{g} / \mathrm{ml}$ ) is required for biofilm eradication. Of note, several investigations has evinced that Gram-positive cocci might have tolerance to vancomycin and other cell wall-effective antibiotics; besides, the molecular and phenotypic mechanisms of this bacterium are still unclear (32-34).

Abranches et al. (35) have reported that tolerance is related to the intracellular level of (p) ppGpp, and mutation in (p) ppGpp- regulator (re/Q) leads to reduction of vancomycin tolerance. In another report, Abranches and coworkers (36) directed inherently tolerance to cell wall-effective antibiotic due to metabolic downshift by suppressing of genes that implicated in translation, transport, energy metabolism and binding. Furthermore, Brauner et al. (37) have highlighted discrepancy among resistance, persistence, and tolerance, which the last two has been classified as time-dependent and dose-dependent persistence as well as tolerance by slow growth and by lag, respectively. It would also be of interest to know that they have suggested that resistance and tolerance are the characteristics of whole bacterial populations, while persistence is a strategy to survive a subpopulation of a clonal bacterial population. Thus, given that only 3 persister were identified, increasing tolerance of biofilm-producing $E$. faecalis isolates against vancomycin would reflect the obscure mechanism of antibiotic tolerance of non-persister cells. The enzymatic lysis assay is the most appropriate method for persister isolation because it is not affected by environmental conditions and has a potential ability to discriminate between two types of persister cells. Using this method, we identified only 3 isolates as persister. Conventional antibiotic assay is dependent on environmental conditions, and more importantly, antibiotics can induce stress response and also leads to increasing persister cells (20).

Persister killing by the anti-cancer drug was subsequent focus of our study. MMC was effectively affected planktonic cells but could not thoroughly eradicated biofilm. Our result was in agreement with that of Kwan et al. (21) who denoted that MMC was unable to completely eliminate biofilm dispersal. Chowdhury et al. (38) have also determined that the anticancer drug such as cisplatin can fully eradicate biofilms which could be an effective treatment. Currently, numerous methods have been designed for the dispersal of biofilm dispersion but it should be noted that the dispersion of persistercontaining biofilm might leads to persister dissemination and recurrent infection that anti-persister treatment needs to be considered.

In this study, we evaluated the expression of biofilm-related genes (esp, agg, gelE) in persister and non-persisters of biofilmproducing $E$. faecalis isolates. We determined that the expression biofilm-related genes were higher in persister than nonpersisters E. faecalis isolates. There was a difference between the expression of these genes in the persister and nonpersister isolates, which can highlight this function in the persister cells. However, our result would confirm this hypothesis that biofilm is a strategy for survival of persisters, but further studies is necessitated to completely prove this hypothesis, because we only studied 3 persister isolates. If this hypothesis is completely proven, a hypothesis arises whether might be a common mechanism for the simultaneous regulation of these two types of phenotypic resistance. Several studies have been supported that toxin-antitoxin system play a key role in biofilm formation and persistence that could be an evidence to this hypothesis.

\section{Conclusion}

\section{Conclusion}

This study highlighted that the associated biofilm-related genes in the persister cells are expressed at a higher rate in comparative with non-persister cells.

\section{Declarations}

\section{Author contribution}


Dr Iraj Pakzad and Vahab Hassan Kaviar contributed to the conception, design of the work, acquisition, analysis and interpretation of data. Abbas Maleki and Sanaz Yarahmadi contributed in administrative, technical, and material support Ebrahim Kouhsari, Saeed Khoshnood and Vahab Hassan Kaviar contributed in drafting of the manuscript, revising and final approval of the version to be published.

\section{New sequences}

Not detected in this study.

\section{Conflict of interest}

The authors report no conflicts of interest in this work.

\section{Ethics approval and consent to participate and publish}

This investigation was approved by the Medical Research and Ethics Committee of Ilam University of Medical Science (IR.MEDILAM.REC.1397.046) (Ethics approval number: 971013/38).

\section{Funding Statement}

This research was supported by Ilam University of Medical Sciences, llam, Iran. The funders had no role in study design, data collection and analysis, decision to publish, or preparation of the manuscript.

\section{References}

1. Arias CA, Murray BE (2012) The rise of the Enterococcus: beyond vancomycin resistance. Nat Rev Microbiol 10(4):266-278

2. García-Solache M, Rice LB (2019) The Enterococcus: a model of adaptability to its environment. Clin Microbiol Rev 32(2):e00058-e00018

3. Werner G, Coque TM, Franz CM, Grohmann E, Hegstad K, Jensen L et al (2013) Antibiotic resistant enterococci-tales of a drug resistance gene trafficker. Int J Med Microbiol 303(6-7):360-379

4. Hughes D, Andersson DI (2017) Environmental and genetic modulation of the phenotypic expression of antibiotic resistance. FEMS MicroBiol Rev 41(3):374-391

5. Ciofu O, Rojo-Molinero E, Macià MD, Oliver A (2017) Antibiotic treatment of biofilm infections. Apmis 125(4):304-319

6. Lebeaux D, Ghigo J-M, Beloin C (2014) Biofilm-related infections: bridging the gap between clinical management and fundamental aspects of recalcitrance toward antibiotics. Microbiol Mol Biol Rev 78(3):510-543

7. Corona F, Martinez JL (2013) Phenotypic resistance to antibiotics. Antibiotics 2(2):237-255

8. Lewis K (2008) Multidrug tolerance of biofilms and persister cells. Springer, Bacterial Biofilms, pp 107-131

9. Zhang Y, Yew WW, Barer MR (2012) Targeting persisters for tuberculosis control. Antimicrob Agents Chemother 56(5):2223-2230

10. Lewis K (2007) Persister cells, dormancy and infectious disease. Nat Rev Microbiol 5(1):48-56

11. Lewis KJNRM. Persister cells, dormancy and infectious disease. 2007;5(1):48-56

12. Conlon BP, Rowe SE, Lewis K (2015) Persister cells in biofilm associated infections. Springer, Biofilm-Based Healthcare-Associated Infections, pp 1-9

13. Weinstein MP, Limbago B, Patel J, Mathers A, Campeau S, Mazzulli T et al (2018) Performance standards for antimicrobial disk susceptibility tests. In: M100 standard, 28th edn. Clinical and Laboratory Standards Institute, Wayne 
14. Hashem YA, Amin HM, Essam TM, Yassin AS, Aziz RK (2017) Biofilm formation in enterococci: genotype-phenotype correlations and inhibition by vancomycin. Scientific reports 7(1):5733

15. Queipo-Ortuño MI, Colmenero JDD, Macias M, Bravo MJ, Morata P (2008) Preparation of bacterial DNA template by boiling and effect of immunoglobulin $\mathrm{G}$ as an inhibitor in real-time PCR for serum samples from patients with brucellosis. Clin Vaccine Immunol 15(2):293-296

16. Shepard BD, Gilmore MS (2002) Differential expression of virulence-related genes in Enterococcus faecalis in response to biological cues in serum and urine. Infect Immun 70(8):4344-4352

17. Zheng J-X, Wu Y, Lin Z-W, Pu Z-Y, Yao W-M, Chen Z et al (2017) Characteristics of and virulence factors associated with biofilm formation in clinical Enterococcus faecalis isolates in China. Frontiers in microbiology 8:2338

18. Singh S, Singh SK, Chowdhury I, Singh R (2017) Understanding the mechanism of bacterial biofilms resistance to antimicrobial agents. The open microbiology journal 11:53

19. Jefferson KK, Goldmann DA, Pier GB (2005) Use of confocal microscopy to analyze the rate of vancomycin penetration through Staphylococcus aureus biofilms. Antimicrob Agents Chemother 49(6):2467-2473

20. Cañas-Duarte SJ, Restrepo S, Pedraza JM (2014) Novel protocol for persister cells isolation. PLoS One 9(2):e88660

21. Kwan BW, Chowdhury N, Wood TK (2015) Combatting bacterial infections by killing persister cells with mitomycin C. Environ Microbiol 17(11):4406-4414

22. Bjarnsholt TJA. The role of bacterial biofilms in chronic infections. 2013;121:1-58

23. Donlan RM (2002) Costerton JWJCmr. Biofilms: survival mechanisms of clinically relevant microorganisms 15(2):167-193

24. Waters EM, Rowe SE, O'Gara JP, Conlon BP (2016) Convergence of Staphylococcus aureus persister and biofilm research: can biofilms be defined as communities of adherent persister cells? PLoS pathogens 12(12):e1006012

25. Moghimbeigi A, Moghimbeygi M, Dousti M, Kiani F, Sayehmiri F, Sadeghifard N et al (2018) Prevalence of vancomycin resistance among isolates of enterococci in Iran: a systematic review and meta-analysis. Adolescent health medicine therapeutics 9:177

26. Hancock LE, Perego M (2004) The Enterococcus faecalis fsr two-component system controls biofilm development through production of gelatinase. J Bacteriol 186(17):5629-5639

27. Klibi N, Ben Slama K, Sáenz Y, Masmoudi A, Zanetti S, Sechi LA et al (2007) Detection of virulence factors in high-level gentamicin-resistant Enterococcus faecalis and Enterococcus faecium isolates from a Tunisian hospital. Can J Microbiol 53(3):372-379

28. Tendolkar PM, Baghdayan AS, Gilmore MS, Shankar N (2004) Enterococcal surface protein, Esp, enhances biofilm formation by Enterococcus faecalis. Infect Immun 72(10):6032-6039

29. Singh R, Sahore S, Kaur P, Rani A, Ray P. Penetration barrier contributes to bacterial biofilm-associated resistance against only select antibiotics, and exhibits genus-, strain-and antibiotic-specific differences. Pathogens and disease. 2016;74(6)

30. Stewart PS. Antimicrobial tolerance in biofilms. Microbiology spectrum. 2015;3(3)

31. Butini ME, Abbandonato G, Di Rienzo C, Trampuz A, Di Luca M (2019) Isothermal microcalorimetry detects the presence of persister cells in a Staphylococcus aureus biofilm after vancomycin treatment. Frontiers in microbiology 10:332

32. Moscoso M, Domenech M, García E (2011) Vancomycin tolerance in Gram-positive cocci. Environmental microbiology reports 3(6):640-650

33. Saribas S, Bagdatli Y (2004) Vancomycin tolerance in enterococci. Chemotherapy 50(5):250-254

34. Ladjouzi R, Bizzini A, Lebreton F, Sauvageot N, Rincé A, Benachour A et al (2013) Analysis of the tolerance of pathogenic enterococci and Staphylococcus aureus to cell wall active antibiotics. J Antimicrob Chemother

Page $12 / 13$ 
68(9):2083-2091

35. Abranches J, Martinez AR, Kajfasz JK, Chávez V, Garsin DA, Lemos JA (2009) The molecular alarmone (p) ppGpp mediates stress responses, vancomycin tolerance, and virulence in Enterococcus faecalis. J Bacteriol 191(7):22482256

36. Abranches J, Tijerina P, Avilés-Reyes A, Gaca AO, Kajfasz JK, Lemos JA (2013) The cell wall-targeting antibiotic stimulon of Enterococcus faecalis. PLoS One 8(6):e64875

37. Brauner A, Fridman O, Gefen O, Balaban NQ (2016) Distinguishing between resistance, tolerance and persistence to antibiotic treatment. Nat Rev Microbiol 14(5):320-330

38. Chowdhury N, Wood TL, Martínez-Vázquez M, García-Contreras R, Wood TK (2016) DNA-crosslinker cisplatin eradicates bacterial persister cells. Biotechnol Bioeng 113(9):1984-1992

39. Sedgley C, Nagel A, Shelburne C, Clewell D, Appelbe O, Molander A (2005) Quantitative real-time PCR detection of oral Enterococcus faecalis in humans. Archives of oral biology 50(6):575-583

\section{Figures}

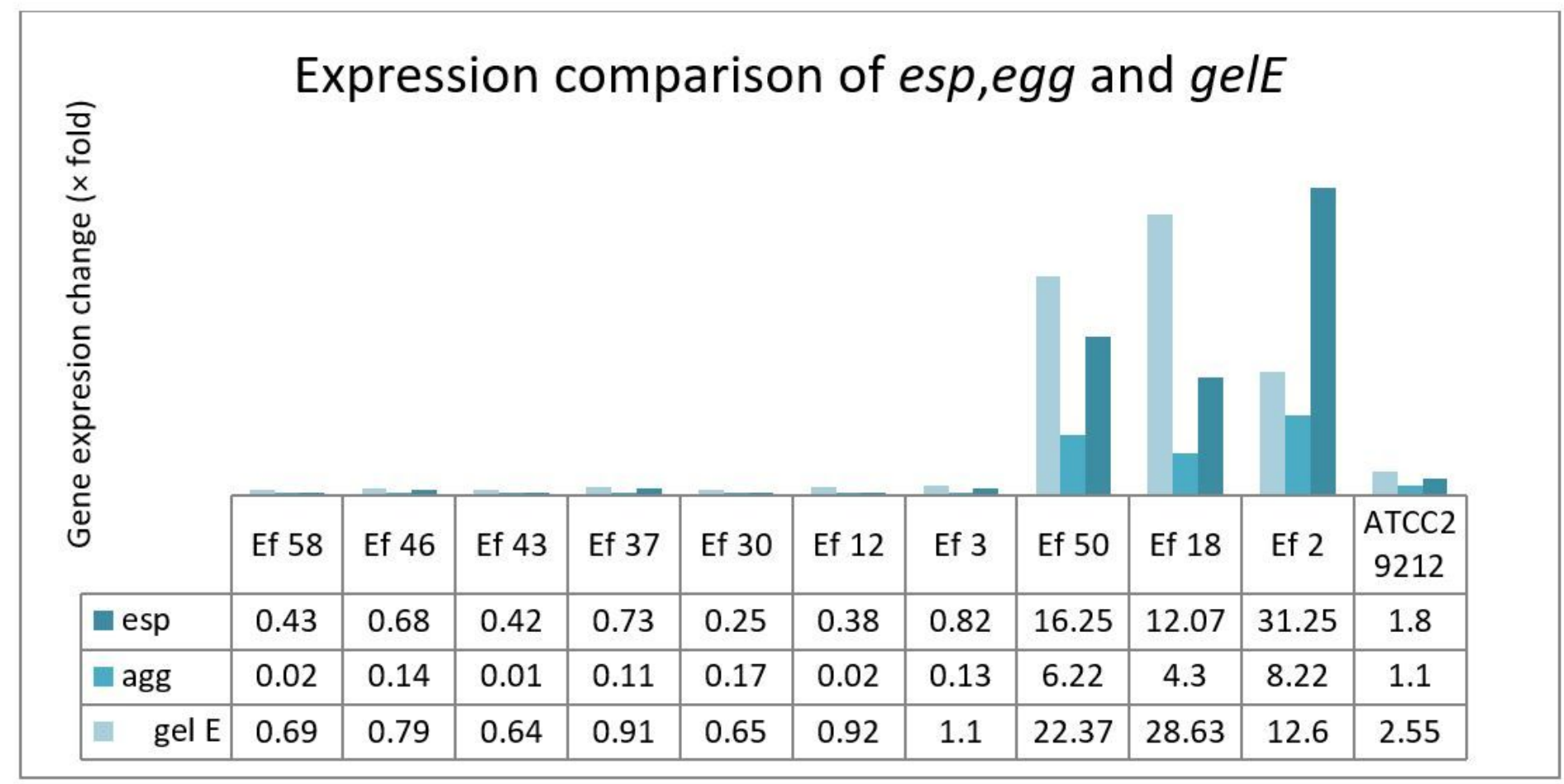

Figure 1

Gene expression comparison of esp, agg and gelE in persister (Ef2, Ef18 and Ef 50) and non-persister isolates (Ef58, Ef46, Ef43, Ef37, Ef 30, Ef12, and Ef3) and E. faecalis ATCC 2921 